\title{
COĞRAFYAYI COĞRAFİ BİLGİ SISTEMLERİ İLE TANIMLAMAK
}

Definıng The Geography By Geographical Informatıon Systems

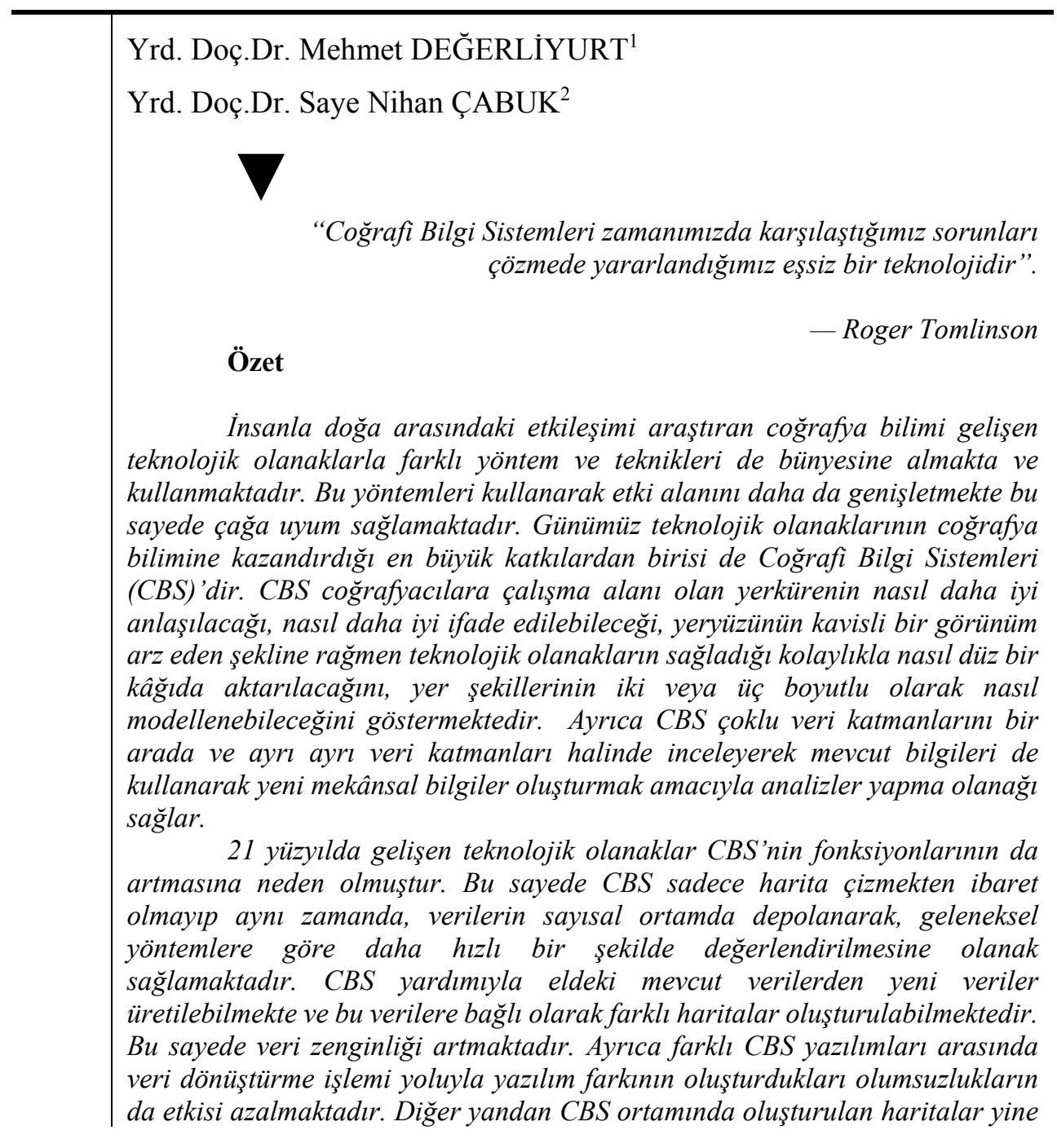

1 Mehmet Akif Ersoy Üniversitesi Fen Edebiyat Fakültesi Coğrafya Bölümü, Burdur, mdegerliyurt1@gmail.com

${ }^{2}$ Anadolu Üniversitesi Yer ve Uzay Bilimleri Enstitüsü, Eskişehir, sncabuk@anadolu.edu.tr 
bilgisayar ortamında rahat bir şekilde saklanabilmekte ve zaman içerisinde güncellenebilmektedir. Bu sayede verilerin eskimesi ve güncelliğini kaybetmesinin önüne geçilmektedir.

Anahtar Sözcükler: Coğrafi Bilgi Sistemleri (CBS), Coğrafya, Kartografik Harita Üretimi

\section{Abstract}

Geography, which investigates the interaction between humans and nature, both incorporates and uses different methods and techniques through the developing technological resources. It further extends its area of impact by using these methods and thus, it complies with the era. One of the most important contributions of today's technological resources brought in the geography is also Geographical Information Systems (GIS). GIS shows the geographers how to better understand and express their study area, the earth, how to easily write it down into a plain paper by means of technological resources despite the curved shape of the earth and how to model the landforms in 2D and 3D. Furthermore, GIS allows us to perform analysis in order to generate new spatial data by examining the multiple data layers all together or one by one as well as using the existing data.

In twenty-first century, technological resources led to an increase in functions of GIS. Thus, GIS is not solely made up of mapping and also makes it possible to evaluate the data faster by storing in the numeric field compared to the traditional methods. With the help of GIS, it is possible to generate new data from available data and create different maps depending on these data. By means, affluence of data increases. Moreover, the negative effects of problems arise from data conversion between different GIS software are reduced. On the other hand, the maps that were generated in GIS environment could also be easily stored in a computer and updated over time. Thus, it is prevented that the data become old and lose their up-to-dateness.

Key Words: Geographical Information Systems (GIS), Geography, Cartographic Map Production 


\section{Giriş}

İnsanla doğa arasındaki etkileşimi araştıran coğrafya bilimi gelişen teknolojik olanaklarla farklı yöntem ve teknikleri de bünyesine almakta ve kullanmaktadır. Bu yöntemleri kullanarak etki alanını daha da genişletmekte bu sayede çağa uyum sağlamaktadır. Günümüz teknolojik olanaklarının coğrafya bilimine kazandırdığı en büyük katkılardan birisi de Coğrafi Bilgi Sistemleri (CBS)'dir. CBS, coğrafi referanslı her türlü mekânsal veriyi entegre olarak depolayan, yöneten, analiz eden, modelleyen, sorgulayan ve çıktı olarak bize sunan yazııım, donanım, kullanıcılar, yöntemler ve coğrafi bilgi bileşenlerinden oluşan bir sistem bütünüdür (Web 1; Fazal, 2008). Bu işlem mekânsal referanslı bilgisayar veri tabanı ve bu veri tabanını çalıştıracak uygun yazılımla yapılır (Fazal, 2008). CBS, oluşturulan yazılım, donanım, veri, yöntem ve kullanıcılardan oluşturulan bu bütünlük sayesinde yeryüzünde bir anlam ifade eden coğrafi referanslı her unsuru elektronik ortama aktarma olanağı sağlar. Aynı zamanda bu unsurları veya olayları haritaya dönüştürerek verileri analiz etmek için gerekli olan bilgisayar desteğini sağlar ve ortak veri tabanlarının da birleștirilmesine yardımcı olur (Yomralıŏlu, 2005). Bu veri tabanlarının yönetimini sağlayarak farklı harita kombinasyonları olușturulmasını sağlar. Tablo ve bilgisayar destekli tasarım (CAD) çizimleri arasında ilişki kurulmasını sağlar. Bu ilişkileri de kullanarak oluşturulan veritabanı yönetim sistemiyle yeni haritalar üretilir ve haritalar üzerinde değişiklikler yapılarak haritaya yansıtılması sağlanır (Fazal, 2008). CBS harita çizimi ve mekânsal verilerin depolanmasına olanak sağlayan tematik haritaların oluşturulmasında kullanılmakta yeryüzündeki coğrafi unsurları ayrı ayrı veya bir arada semboller halinde belirli bir görsellik dâhilinde sunma olanağı sunar. Bu özelliği ile CBS coğrafya bilimine önemli ölçüde yardımcı olur. Çünkü coğrafya bilimi, mekânı sadece üzerinde çalışlan bir saha olarak ele almamakta, görünen ve görünmeyen özellikleri ile mekânı adeta yaşayan bir organizma olarak değerlendirip bu yolla onu anlamaya, kullanmaya, şekillendirmeye ve yönetmeye çalışmaktadır (Demirci, 2008). Bu yüzden CBS coğrafyacılara onların çalışma alanı olan yerkürenin nasıl daha iyi anlaşılacağı, nasıl daha iyi ifade edilebileceği, yeryüzünün kavisli bir görünüm arz eden şekline rağmen teknolojik olanakların sağladığı kolaylıkla nasıl düz bir kâğıda aktarılacağını, yer şekillerinin iki veya üç boyutlu olarak nasıl modellenebileceğini göstermektedir (Mulcahy, 2004). Ayrıca CBS çoklu veri katmanlarını bir arada ve ayrı ayrı veri katmanları halinde inceleyerek mevcut bilgileri de kullanarak yeni mekânsal bilgiler oluşturmak amacıyla analizler yapma olanağı sağlayan bir araçtır (Decker, 2001).

Coğrafya bilimi yeryüzünün fiziki ve beşeri özelliklerini tarif ederken CBS ortamında oluşturulan haritaları kullanmaktadır. CBS'nin coğrafya bilimi içerisindeki etkinliği ise her geçen gün artmaktadır. Özellikle 2000'li yıllardan sonra bu durum daha da hızlanmıştır. Bu bağlamda Coğrafi Bilgi Sistemleri (CBS), doğal afetler yönetimi, ağ analizleri yardımıyla en kısa yol analizlerini kullanarak güzergâh belirlenmesi, sağlık planlaması, kentsel planlama ve kaynak aktarımı işleri gibi hayatımızın hemen hemen her yönünde kullanılır hale gelmiştir. Bunda CBS'nin kullanıcı kitlesinin gelişmesinin de rolü vardır. Çünkü CBS sadece birkaç yıl önce araştırmacılar, planlamacılar ve bazı kamu kurumları gibi sınırlı bir kitle tarafından kullanılıyorken, artık günümüzde birçok kişi tarafında tematik harita oluşturma veya çakıştırma analizi (overlay) gibi işlemlerin yapılmasında kullanılabilmektedir. Öte yandan, gelişmiş araçlar ve özel uzmanlık gerektiren 
kentsel ve bölgesel planlama, çevre koruma ya da iş yönetimine ilişkin birçok karmaşık sorunun çözümünde mevcut CBS teknolojisi mekânsal analizler, modelleme ve simülasyonlar yaygın olarak kullanılmaktadır (Neteler, ve Mitasova, 2004).

\section{CBS Günümüze Kadar Nasıl Bir Gelişim Süreci İzlemiştir?}

Coğrafi Bilgi Sistemleri (CBS) tarihçesi aslında insanoğlunun tematik harita gereksinimi ile birlikte başlamıştı. Her ne kadar o günlerde bilgisayar olmasa da, farklı temalarda harita üretimi ile CBS'nin temelleri atılmıştır. Buna en çarpıcı örnek, 1819 yılında modern istatistiğin ilk tematik haritası, Fransız Pierre Charles Dupin tarafından, siyah beyaz tonlama ve farklı tarama yöntemleri kullanılarak üretilmiştir. Dupin'in Fransa'daki cehalet ve eğitimsizliğin dağılımını göstermek amacı ile ürettiği harita, CBS'nin temel taşı olarak gösterilmektedir (Uyguçgil, 2011). Diğer bir çalışma ise İngiliz fizikçi ve epidemiyolojist olan ve modern epidemiyolojinin kurucusu olan John Snow'un 1854'te Londra'da meydana gelen kolera salgının kaynağını ortaya koyma amacıyla yapmış olduğu tematik haritadır (Şekil 1). Onun bulguları Londra ve dünyanın diğer şehirlerinde su kaynakları ve atık sistemlerinin geliştirilmesinde, buna bağlı olarak halk sağlığının iyileştirilmesinde dikkat çekici ilerleme olmasını sağlamıştır (Web 2). Snow çalışmasında salgın hastalıkların kontrolünü amaçlamış ve kolera sonucu ölümleri noktasal harita üzerinde göstermiştir. 1940 'lı yılların sonlarına doğru elektronik bilgisayarın üretimi ile bilgisayar çağının başlaması, CBS'nin gelişimini hızlandıran en önemli etkenlerden biridir. Temel ilke olarak CBS, doğrudan bilgisayar teknolojisine gerek duymasa da, entegre sistemler haline dönüşmesindeki en önemli etkendir (Uyguçgil, 2011).

CBS'nin çıkışında o dönemde Harvard Üniversitesi Peyzaj Mimarlı̆̆ Bölümünde yer alan Computer Lab'in oldukça önemli etkisi olmuştur. 1960'll yıllarda kurulan bu laboratuvarda günümüzde coğrafi bilgi sistemlerinin yaygınlaşmasında önemli olmuş pek çok kişi lisans üstü eğitimleri sırasında görev almıştır. Bu kişiler arasında bugün CBS sektöründe yaygın kullanılan ESRI, Intergraph firmalarının kurucuları da yer almıştır. Başlangıçta belirtilen sisteme isim verilirken, sistemin isminin peyzaj bilgi sistemi olması konusunda bazı görüşler atılmış olsa da, o dönemde bu sistemin isminin daha genelleştirilmesi ve farklı meslek disiplinlerinin de kullanımının gerekliliği doğrultusunda sistemin ismi coğrafi bilgi sistemleri olarak belirlenmiştir. Gerçekten de bakıldığında coğrafi bilgi sistemleri coğrafya içerisinde tanımlı olan pek çok farklı bileşeni analiz etmek için kullanılması gereken önemli bir araçtır ve bu ismiyle kısa zamanda ticarileşmiş ve farklı sektörler için artık kullanılması kaçınılmaz bir araç ve bir bilim dalı olarak ortaya çıkmıştır.

CBS bilgisayar teknolojisiyle koşut olarak gelişmiştir. Bilgisayar teknolojisinin gelişmesi CBS'nin günlük hayattaki etkinliğinin her geçen gün artmasına neden olmuştur. Bilgisayar teknolojisinin 1980 'lerden itibaren kullanımının yaygınlaşması, hazırlanan grafik ve haritaların bilgisayar ekranlarında görsel olarak daha rahat tasarlanmasına olanak sağlamıştır. Piyasaya yeni CBS yazılımlarının çıkması bilgisayar ortamında haritacııık yapılmasını, bilgisayar ortamında kantitatif modellerin ve mekânsal istatistik çalışmalarının yapılmasını kolaylaştırmışıı (Chrisman, 1988; Batty, 2010). Uzaktan algılama yoluyla veri toplama olanaklarının artması, bu verilerin CBS ile bağlantılı kullanılabilmesi ve elde edilen verilerin teknolojik olanaklar sayesinde web ortamında kullanıcılıların hizmetine sunulabilmesini sağlamıştır (Batty, 2010). 


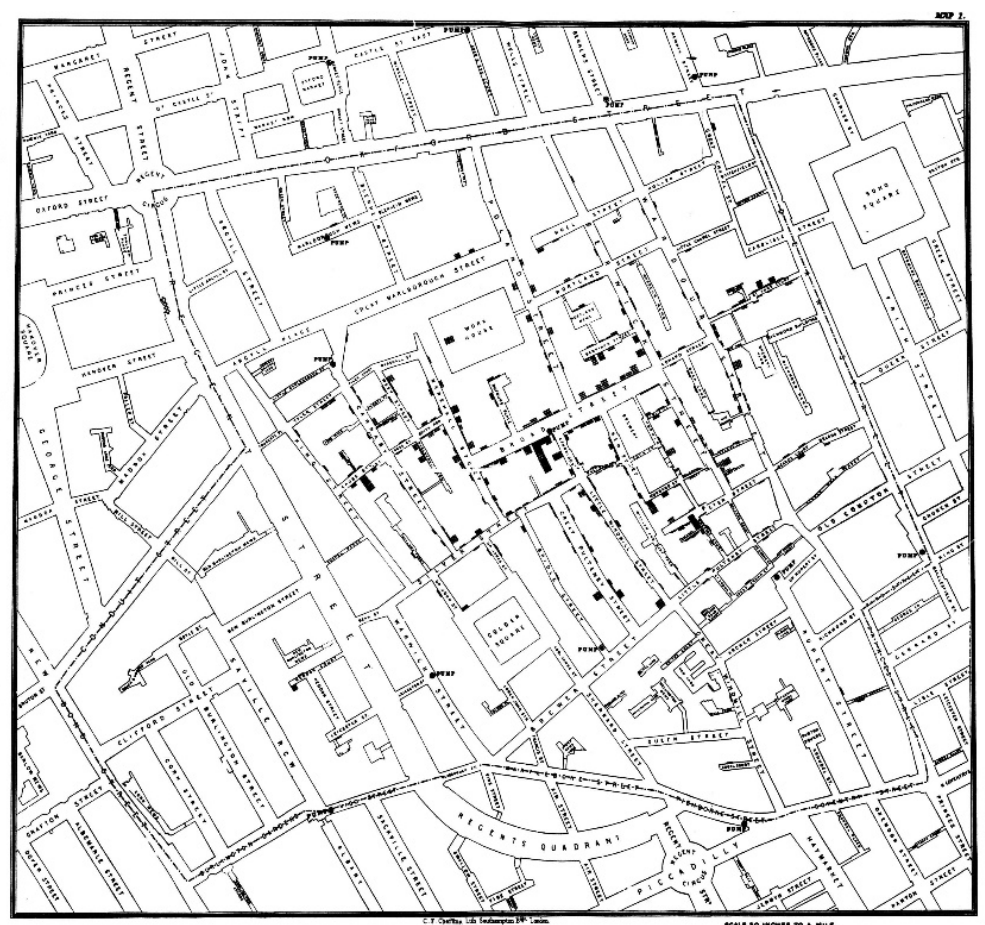

Şekil 1. John Snow Tarafından Çizilen Su Kuyuları ve Kolera Vakalarını Gösteren Tematik Harita (Web 2)

\section{Betimleme Aracı Olarak CBS}

Bilindiği gibi coğrafya kelimesi Grekçede yeryüzü anlamına gelen "geo" ile yazma, çizme ve tasvir anlamına gelen "graphica veya graphein" sözcüklerinin birleşmesiyle elde edilen "geographica" veya "geographein" terimleri yeryüzünün görünen, bilinen, keşedilen özelliklerinin betimsel (tasviri) olarak aktarımı anlamına gelmektedir (Özçağlar, 2006). CBS Coğrafya biliminin tasvir amacına uygun olarak yeryüzündeki coğrafi unsurları nokta, çizgi ve çokgen (poligon) olarak gösterebilme olanağı sağlamaktadır. Bu sayede bilgisayar ortamına aktarılan veriler kullanılarak tematik haritalar oluşturulabilmektedir. Bu haritalar sadece tek bir konuyu içerebildiği gibi birden fazla konuyu da içermekte ve bir arada tek haritayı oluşturabilmektedir. Örneğin, tarım, madencilik, sanayi gibi, bir yere ait ekonomik faaliyetlerin her birisi için tek tek haritalar oluşturulabildiği gibi, bu özelliklerin her birisi için oluşturulan katmanların birleştirilmesiyle ekonomik etkinlik haritası da oluşturulabilir (Şekil 2).

CBS'nin yeryüzüne ait olay ve olguları tasvir etme özelliği her bir disiplin açısından farklılık göstermektedir. Bu konuda De By vd. (2001), bir şehir plancısının kentin gelişmesi, nüfus artışı ve kentsel niteliğin ortaya konulması konusunda, bir biyolog, nüfus artışı için uzun vadeli tehditlere karşı daha iyi önlem almak, çeşitli ekosistemlerdeki türlerin dağılışını 
Coğrafyayı Coğrafi Bilgi Sistemleri ile Tanımlamak

takip edebilmeyi, doğal afet yöneticisi için doğal afet risk alanlarının ortaya konularak alınması gereken önlemlerle ilgili çalışmalar yapmada, bir jeoloji mühendisinin kaya oluşumu özelliklerine bakarak depremler ile yeni yerleşim alanları inşa etmek için en uygun alanları belirleme çalışmaları yaparken, bir maden mühendisi madenlerin, kapsamı, derinliği ve cevher kütlesinin kalitesini araştırırken ve çeşitli parametreleri dikkate alarak, olası maden alanlarının belirlenmesinde, bir orman mühendisi toprak ve ağaç, çeşitliliğini korumak için gerekli operasyonel kısıtlamaları yapmada, hidrolog ya da hidroloji mühendisi için mevcut içme ve kullanma suyu dağıtımı ve kullanılmış suyun uzaklaştırılması, tatlı su kaynaklarına ait su kalitesinin ortaya konulmasında kullanabileceğini belirtmiştir.

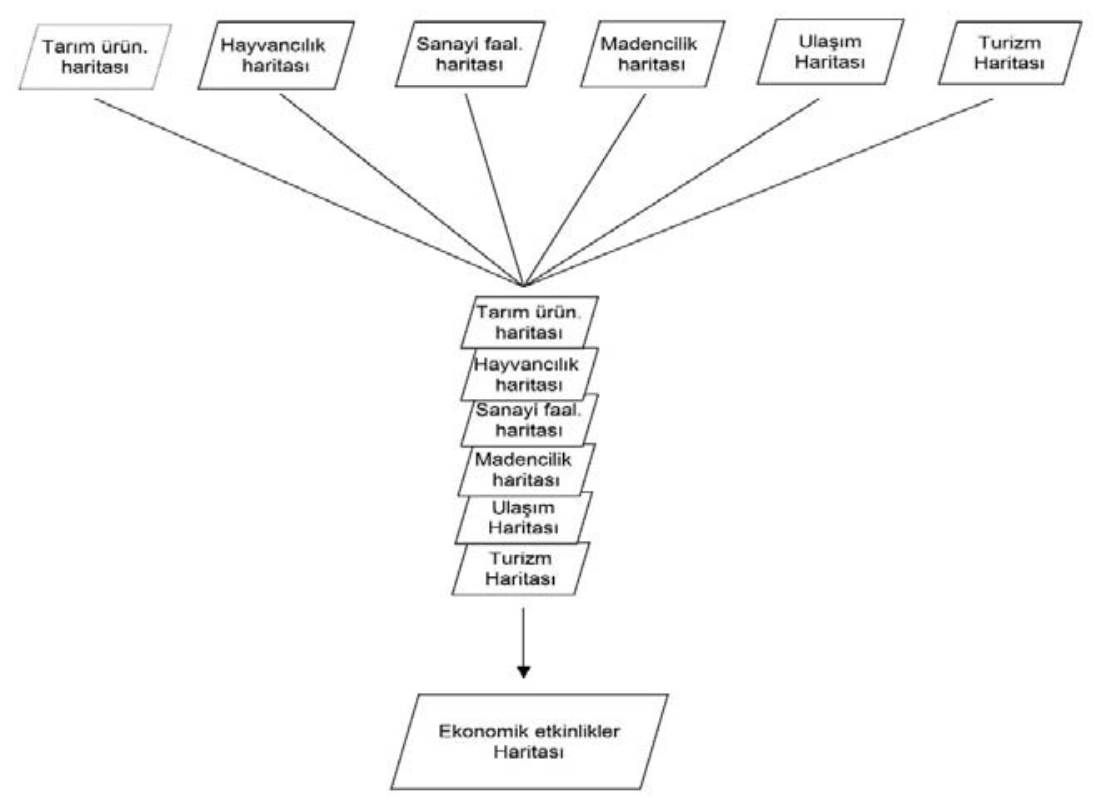

Şekil 2. Bir Yere Ait Ekonomik Etkinlik İçin Hazırlanan Haritaları ve Bu Haritaların Birleştirilmesiyle Oluşturulan Birleşik Ekonomik Etkinlik Haritası

CBS, coğrafi referanslı bilgileri bilgisayar ortamında etkin bir şekilde kullanarak analizler yapılmasını sağlar. Yapılan analizlerden elde edilen çıktıları görsel materyallere dönüştürür. Oluşturulan veri tabanlarına yüklenilen verilerin düzenlenmesi, yönetilmesi ve bir takım matematiksel işlemlerin yapılmasına olanak sağlar. Örneğin bir yere ait nüfus ve yüzölçümü verileri mevcutsa bu verilere ait ayrı ayrı haritalar oluşturulabileceği gibi nüfus sütununu, yüzölçümü sütununa bölerek nüfus yoğunluğu haritası da oluşturulabilir. Bu harita eldeki mevcut veriler kullanılarak oluşturulmuş yeni bir harita olacaktır (Tablo 1). 
Tablo 1. Örnek Bir Öznitelik Tablosu

\begin{tabular}{|c|c|c|c|c|}
\hline ID & Ad1 & Nüfusu & Yüzölçümü $\left(\mathrm{m}^{2}\right)$ & Metrekareye düşen kişi sayısı \\
\hline 1 & A & 30.000 & 300.000 & 0.1 \\
\hline 2 & B & 20.000 & 400.000 & 0.05 \\
\hline 3 & C & 50.000 & 100.000 & 0.5 \\
\hline 4 & D & 45.000 & 180.000 & 0.25 \\
\hline
\end{tabular}

Diğer yandan bir yere ait farklı özellikteki katmanların çakıştırılmasıyla (Overlay) o yere ait, farklı uygunluk haritaları oluşturulabilir (McHarg, 1992). Bu işlemin yapılmasında bir yerin farklı özelliklerini ifade eden katmanların coğrafi referanslı veri tabanlarına aktarılması ve aynı veri formatına dönüştürülmesi gerekmektedir. Oluşturulan raster formattaki her haritayı oluşturan piksellere rakamsal değerler verilmektedir. Bu rakamsal değerlerin çarpımından oluşan çakıştırma işlemi matematiksel bir işlem olup, aynı anda milyonlarca işlemin yapılabilmesine olanak sağlamaktadır. Bu işlem sonucunda da değişik özellikteki katmanların analizinden yine farklı bir harita çıkmaktadır (Şekil 3). Coğrafi bilgi sistemlerinin kullanımının yaygınlaşması ile ilgili pek çok referansa göre, CBS'nin çıkışında Ian Mc Harg'ın Design with Nature kitabında yer alan çakıştırma kuramının çok önemli etkisi olmuştur. Bir peyzaj plancısı olan Mc Harg, bu kuramında coğrafyaya ya da mekana dair bir karar verilirken, o mekana ait pek çok özelliğin bir arada değerlendirilmesi gerektiğine vurgu yapmış, bu işlemin de bu katmanların üst üste çakıştırılarak yapılabileceğini belirtmiştir. Ayrıca Mc Harg, kitabında değerlendirilmesi gereken veri sayısının beşin üzerinde olması halinde, bunun insanın muhakeme yeteneğiyle sağlıklı şekilde yapılmasının olanaksız olduğunu belirtmiştir. İşte bu saptamalar, özellikle mekana ya da coğrafya dair bir karar üretilirken, sağlıklı ve doğru sonuç üretebilmek için CBS gibi bir teknolojiyi zorunlu hale getirmiştir.
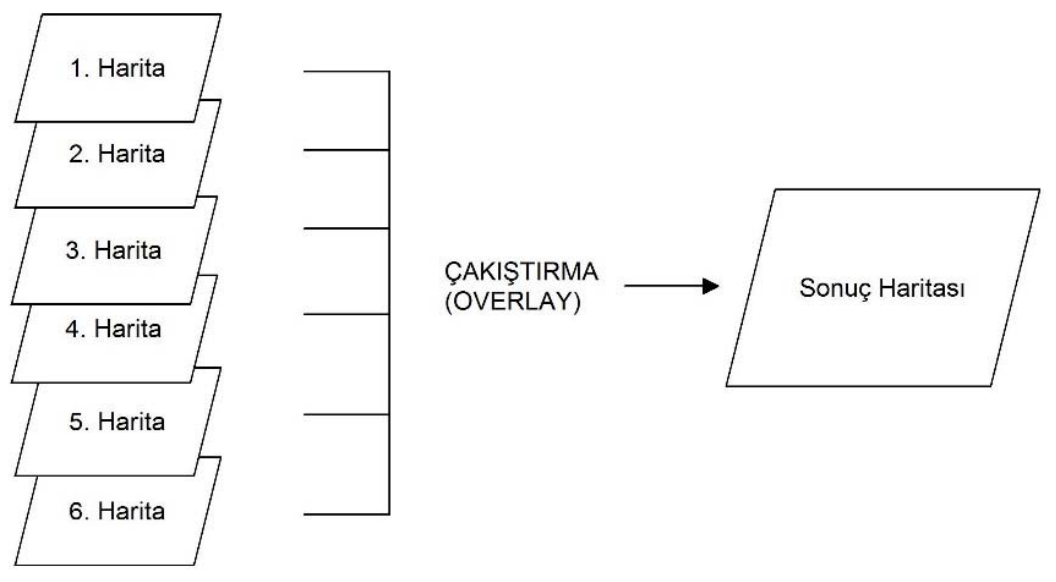

Şekil 3. Çakıştırma (Overlay) Analizi 


\section{Görselleştirme Aracı Olarak CBS}

CBS yardımıyla oluşturulan haritalar istenilen şekilde tasarlanarak sunuma hazır duruma getirilir. $\mathrm{Bu}$ işlemin yapılmasında harita hazırlayan kişinin becerisi ve kartografya bilgisi önemlidir. Çünkü kartografya haritaların arka planındaki çizim, kullanma ve prensiplerle ilgilenen bilim dalıdır. Bu yüzden de CBS konusunda çalışma yapan kişinin az da olsa kartografya bilgisine sahip olmasi gerekmektedir (Clarke, 2003).

CBS, yersel ölçme, fotografik yöntemler, uzaktan algılama, GPS yardımıyla veri toplanması, mevcut haritaların elle sayısallaştııılması, hazır veri tabanlarının transferi ve tarama yoluyla sayısallaştırılarak elde edilen verilerin bilgisayar ortamına aktarılmasıyla ihtiyacı olan malzemeyi elde eder (Yomralığlu, 2005). Bu malzemelerden bazıları 2 boyutlu iken bazıları 3 boyutludur. CBS güçlü veri transfer yeteneği sayesinde verileri aynı veri tabanı içerisinde toplayabilmekte bu verileri analiz ederek istenilen haritanın hazırlanmasını sağlar. Görsel açıdan zengin haritalar üretilmesini sağlar. CBS'nin görsellik açısından en önemli özelliklerinden birisi de yeryüzüne ait fiziki veya beşeri unsurların 2 boyuttan 3 boyuta dönüştürülmesidir. Bu işlem birkaç aşamadan oluşmaktadır. İlk olarak iki boyutlu bir vektör veri olan sayısal izohips haritasından düzensiz üçgen ağları (Triangulated Irregular Network-TIN) üretilmektedir. Her üçgen homojenleştirilmiş topografik karakteristikleri belirler. Öznitelik tablosunda her üçgen hücre, hem arazi eğimi, hem de araziye dair diğer temel topografik özelliklere göre kodlanır. Topografyaya ait veriler bu haritalardan türetilebilir (Web 3). Daha sonra bu haritadan sayısal yüksekli modeli (DEM) haritası da elde edilir (Şekil 4).

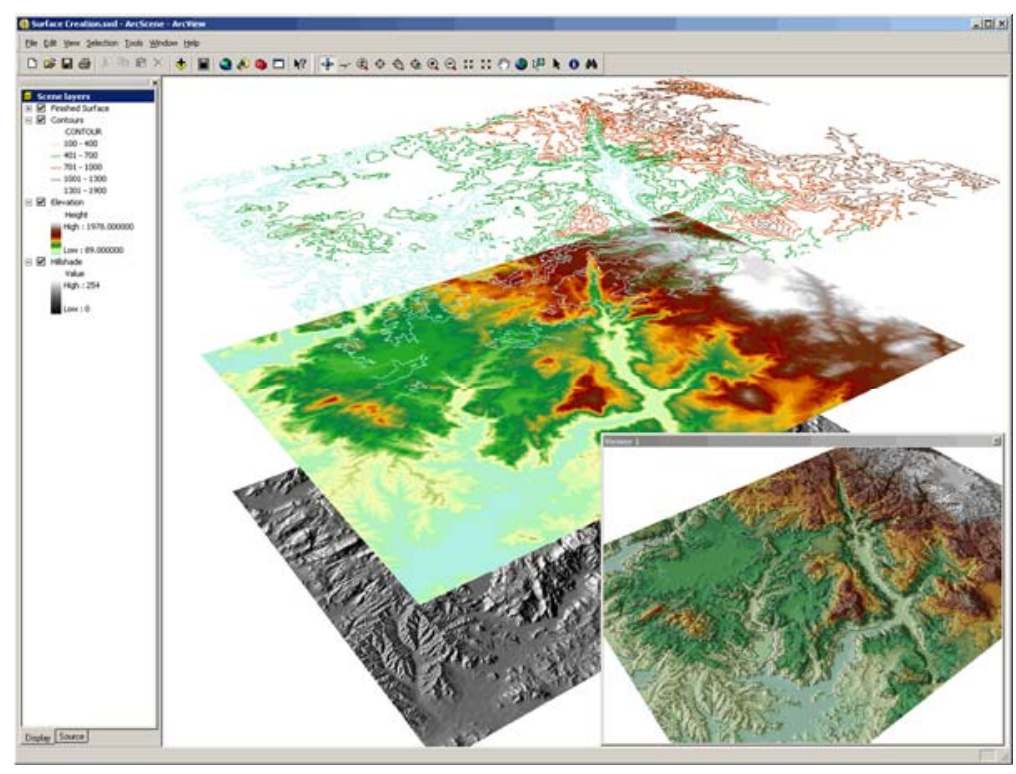

Şekil 4. İzohips Verisinden TIN ve Sayısal Yükseklik Verisi (DEM) Üretilmesi (Web 4) 
Sayısal yükseklik verisi (DEM) üç boyutlu raster bir veri olup, oluşturan her piksel enlem, boylam ve deniz seviyesinden yükseklik değerlerini içermektedir. Bu özelliği sayesinde araziye ait bazı haritaların üretilmesinde kullanılmaktadır. Örneğin CBS ortamında sayısal yükseklik modeli (DEM) kullanılarak, yükselti kademeleri, eğim, bakı ve gölgelendirme (hillshade) elde edilebilmekte ve bu haritalar bir arada sunulabilmektedir. Şekil 5'de Diyarbakır ilinde küȩük bir alan için yapılmış bir örnek yer almaktadır.

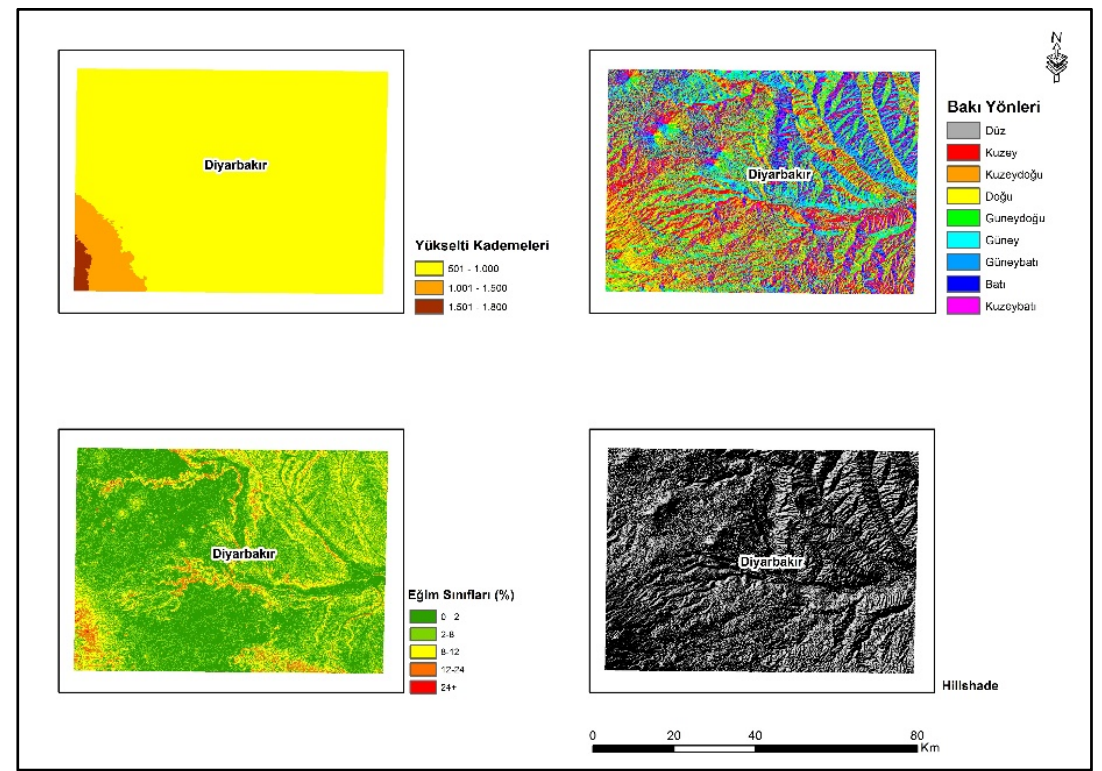

Şekil 5. Diyarbakır’a Ait Bazı Sayısal Haritaların Bir Arada Sunulması

CBS hem fiziki hem de beşeri unsurların 3 boyutlu görülmesini sağlamaktadır (Şekil 6). $\mathrm{Bu}$ şekilde elde edilen veriler gerek vektör tabanlı gerekse raster tabanlı veriler olabilmektedir. Elde edilen görsel malzeme yeryüzünün coğrafi koordinatlı küçük bir modelini oluşturmakta ve ekolojik çalışmalar, çevresel izleme, inşaat mühendisliği ve mimari çalışmalar, maden arama, üç boyutlu kentsel haritalama, peyzaj planlama, savunma ve istihbarat, komuta ve kontrol gibi bir çok alanda kullanılabilmektedir (Abdul-Rahman ve Pilouk, 2008). 


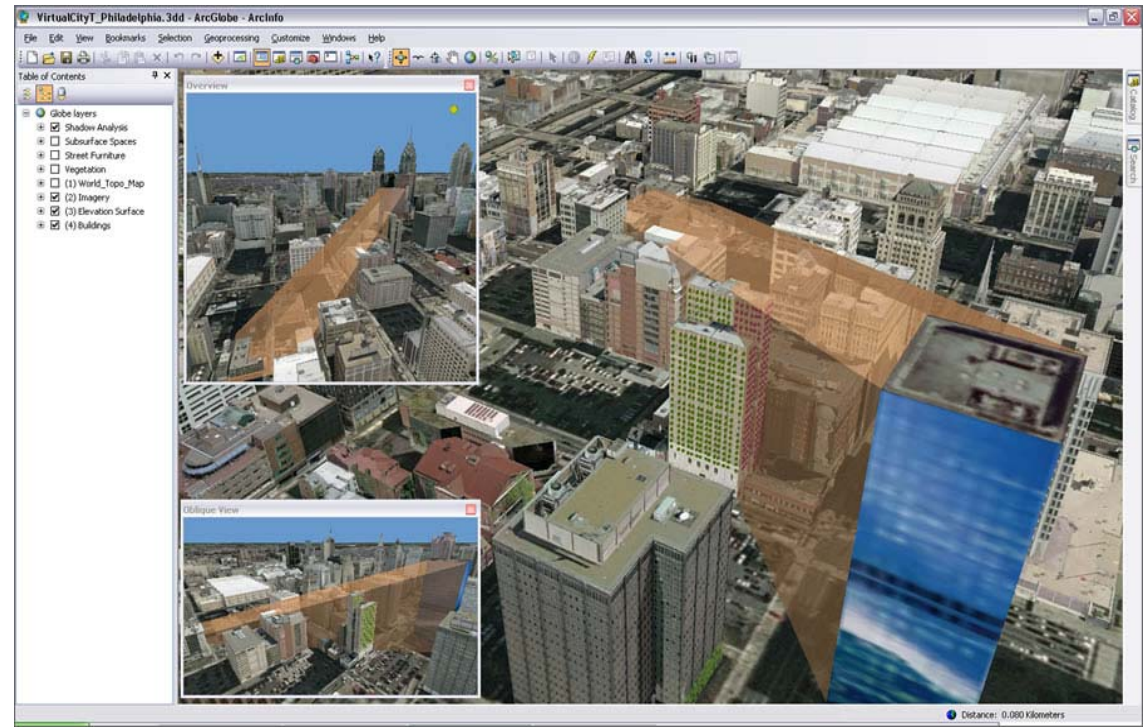

Şekil 6. CBS ortamında binaların 3 boyutlu görülebilirlik analizinin yapılması (Web 5)

CBS web uygulamalarından olan Google Earth gibi online platformlar yardımıyla aslında artık dünyada pek çok kullanıcı tarafından yaygın olarak kullanılmaya başlamıştır. İnternet ortamında en kısa yol analizinden, üç boyutlu arazi görüntüsüne kadar birçok hizmeti bu platformlar yardımıyla çok sayıda kullanıcı hızlı şekilde elde edebilmektedir. Şekil 7.'de Niyagara şelalesinin üç boyutlu görüntüsü görülmektedir. 


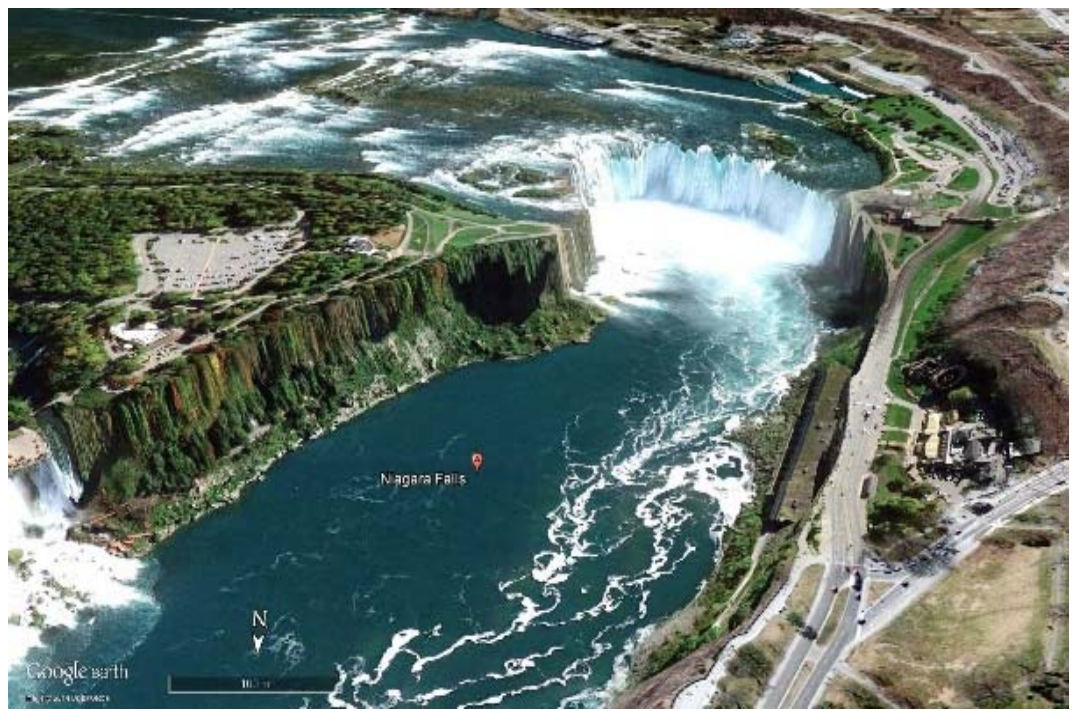

Şekil 7. Niagara Şelalesinin 3 Boyutlu Google Earth Görüntüsü

\section{Sonuçlar}

Gelişen teknolojik olanaklar CBS'nin fonksiyonlarının da artmasına neden olmuştur. Bu sayede CBS sadece harita çizmekten ibaret olmayıp aynı zamanda, verilerin sayısal ortamda depolanarak, geleneksel yöntemlere göre daha hızlı bir șekilde değerlendirilmesine olanak sağlamaktadır. CBS yardımıyla eldeki mevcut verilerden yeni veriler üretilebilmekte ve bu verilere bağlı olarak farklı haritalar oluşturulabilmektedir. $\mathrm{Bu}$ sayede veri zenginliği artmaktadır. Ayrıca farklı CBS yazılımları arasında veri dönüştürme işlemi yoluyla yazılım farkının oluşturdukları olumsuzlukların da etkisi azalmaktadır. Diğer yandan CBS ortamında oluşturulan haritalar yine bilgisayar ortamında rahat bir şekilde saklanabilmekte ve zaman içerisinde güncellenebilmektedir. Bu sayede verilerin eskimesi ve güncelliğini kaybetmesinin önüne geçilmektedir.

Teknoloji çağı olarak bilinen 21. Yüzyılda CBS'nin daha da ilerleme kaydedeceğini söylemek için kâhin olmaya gerek yoktur. Ancak hızlı gelişen bu teknolojiye ayak uydurabilmek ve onu en son yenilikleriyle takip edebilmek başlı başına bir iş ve meşgale olmaktadır. Bu durum insanların CBS'nin belirli alanlarında uzmanlaşmalarını beraberinde getirmektedir. İlerleyen dönemlerde insanların 'CBS kullanıyorum' değil de 'CBS'de şu analiz üzerinde çalışıyorum' demeleri kaçınılmaz olacaktır. Diğer yandan gelişen teknolojik olanaklar sayesinde mobil teknoloji uygulamaları yardımıyla taşınabilir cihazlarda CBS ürünlerini kullanma olanağının doğması CBS'nin daha geniş kitleler tarafından kullanılabilmesinin önünü açmaktadır. Örneğin, arazi çalışmasında CBS ortamına anlık veri girişi yapılabilmekte ve yine bu veriler internet yardımıyla ortak veri tabanlarına aktarılabilmektedir. Bu durum da CBS'nin sadece coğrafyacılar değil, birçok disiplin tarafından kullanılmasının önünü açmaktadır. 
Coğrafyayı Coğrafi Bilgi Sistemleri ile Tanımlamak

\section{Yararlanılan Kaynaklar}

Abdul-Rahman, A., Pilouk, M., 2008, Spatial Data Modelling for 3D GIS, Springer-Verlag Berlin Heidelberg

Batty, M., 2010, Using Geographical Information Systems, (Key Methods in Geography, Eds: Nicholas Clifford, Shaun French, Gill Valentine), SAGE Publications Ltd, USA

Chrisman, N.R. (1988) 'The rise of software: a case study of the Harvard lab', American Cartographer, 15(3): 291-300.

Clarke, C.K., 2003, Getting Started with Geographic Information Systems, Prentice Hall Series in Geographic Information Science (Fourth Edition), USA

De By, R.A., Knippers, R.A., Sun, Y., Ellis, M.C., Kraak, M.J., Weir, M.J.C., Georgiadou, Y., Radwan, M.M.. vanWesten, C.J., Kainz, W., Sides, E.J., 2001, Principles of Geographic Information Systems (An introductory textbook), ITC Educational Textbook Series 1, Netherlands

Decker, D., 2001, GIS Data Sources, John Wiley \& Sons, Inc., USA

Demirci, A., 2008, "Öğretmenler İçin CBS: Coğrafi Bilgi Sistemleri", Fatih Üniversitesi Yayınları

Fazal, S., 2008, GIS Basics, New Age International (P) Ltd., Publishers, New Delhi

MacHarg, I.L., (1992). Design With Nature,John Wiley \& Sons, USA

Mc Harg, I., 1969, Design With Nature, Published 1969 by The Natural History Press, 198 pages, USA

Mulcahy, K. A. 2004, Geography Basics, (Ed.Ray Sumner), Vol 1, Salem Press, USA

Neteler, M., Mitasova, H., (2004), Open Source GIS: A Grass GIS Approach Second Edition, Kluwer Academic Publishers, USA

Özçağlar, A., (2006), Coğrafyaya Giriş (Sistematik, Kavramlar, Yöntemler), Hilmi Usta Matbaacilık, Ankara

Uyguçgil, H., 2009, CBS Veri Tipleri ve Modelleri, (Harita Bilgisi ve Coğrafi Bilgi Sistemlerine Giriş, Ed. Alper Çabuk), Anadolu Üniversitesi yayınları, No:1947, Eskişehir

Yomralığlu, T., 2005, Coğrafi Bilgi Sistemleri Temel Kavramlar ve Uygulamalar (3. Bask1), Akademi Kitabevi, Trabzon

\section{Web adresleri}

Web 1. http://www.esri.com/what-is-gis/overview\#overview panel (Erișim:15.09.2014)

Web 2. http://en.wikipedia.org/wiki/John_Snow (physician)) (Erişim:15.09.2014)

Web 3. http://www.hgk.msb.gov.tr/dergi/makaleler/130 1.pdf (Erişim:15.09.2014)

Web 4. http:/www.unsa.edu.pe/infounsa/wp-content/uploads/2012/11/surface creation.gif (Erişim: 15.09.2014)

Web 5. http://www.esri.com/news/arcwatch/0410/graphics/arcgis10-2-lg.jpg (Erişim:15.09.2014) 